\title{
Analysis of the Pros and Cons of Students' Online Courses during the Epidemic and the Prospects for the Development of English Online Platform in Secondary Vocational School
}

\author{
Qiuyu Huang* \\ Zhanjiang Medium Medical Department School, Zhanjiang 524094, Guangdong Province, China
}

\begin{abstract}
Facing the severe epidemic situation, China's education department has put forward an online teaching emergency plan of "Stopping going to school while keeping teaching online", so that many students in secondary vocational school can avoid close contact back to school and protect their lives and health. At the same time, it guarantees the teaching progress in the special period. Teachers in secondary vocational school prefer to choose DingTalk software to develop online teaching models. In the teaching of the vocational English network platform, online teaching is a reform of the teaching form based on information technology and the Internet. Teachers can use the DingTalk platform to interact with students, so that the online teaching method meets the individual needs of students. It takes good account of students with different English foundations and levels, and greatly stimulates students' interest in learning. This paper analyzes the advantages and disadvantages of online teaching and explores the online teaching model.
\end{abstract}

Keywords: Online teaching; Pros and cons and Countermeasures

Publication date: June, 2020

Publication online: 30 June, 2020

*Corresponding author: Qiuyu Huang, 2387207665@ qq.com

From the perspective of curriculum education, the current online teaching platform and its types are more diverse. And blindly copying the online teaching form of other teachers cannot create an effective online classroom. Regardless of online or offline teaching, teachers can use advanced teaching technology to carry out education and teaching work, cultivate students' self-learning ability, reflecting the innovative development of education teaching forms and concepts. With the help of Internet technology, teachers can break through the limitations of time and space, and plan and formulate online curriculum teaching plans based on the home learning status of students in secondary vocational school. And it provides a large number of online learning resources for students through the DingTalk online teaching platform, which is in line with the current trend of education informatization. Compared with the traditional classroom teaching practice, English teachers get rid of the methods of blackboard writing and dictation, but use the online teaching mode to ensure the teaching during the epidemic, which can make up for the limitations of traditional teaching methods.

\section{Analysis of the advantages of online courses during the epidemic}

\subsection{Interesting teaching scenes}

In the face-to-face classroom teaching practice, teachers can directly transfer the knowledge in the textbook to students. The students' active thinking is difficult to be exercised, and they are only in the passive position of acceptance, and it is difficult to effectively improve the students' English language level. In DingTalk's online teaching, English classes in vocational schools are no longer boring, but they can also highlight the fun of language learning. Teachers draw pictures and provide 
music information according to the teaching content, and transform English learning into a virtual English conversation scene. Students' new learning and learning experience mobilizes their enthusiasm for learning, and transforms the inherent teacher-explained classroom environment into scene of English for students' active learning and dialogue. It can promote the common development of teachers and students' English abilities.

\subsection{Scientific evaluation model}

Starting from the evaluation and reward system of online teaching, teachers use evaluation methods of classroom performance and final score in classroom teaching practice. The main evaluators are peoplecentered, and the evaluation of students is subjective, while the teaching management and evaluation system developed by the network platform is more objective. Among them, the teaching software of DingTalk and other platforms can record the behavior process of teaching and activities between teachers and students in real time, and can conduct comprehensive analysis and evaluation based on the performance of teachers and students. At the same time, the teaching network platform can reflect the deficiencies in each teaching detail of teachers and students. It can also analyze the reasons for the decline in student performance from the outside and psychological aspects. It has formed a complete big data evaluation system that can help teachers and students correct and improve their own deficiencies and develop their own abilities.

\subsection{Teaching resources are free from the limitation of time and space}

The reproducibility of online teaching content helps students learn knowledge deeply. Repetition is the mother of learning. In traditional teaching, although the acceptance abilities of dozens of students are all different, the teacher only teaches the knowledge once in the classroom. Those who understand will be good, but those who do not understand will have no opportunities to learn. The repeatability of online teaching is more suitable for every student than that of traditional classrooms. Students who do not understand at first can listen to the content for one or two more times. Students can also use resource replays for periodic review to consolidate their knowledge. Online teaching has the characteristics of mobile learning. Students are not limited by time and space, and can study anytime and anywhere according to their own characteristics.

\subsection{It reflects awareness of self-learning}

The autonomy of online teaching can provide students with the possibility of personalized learning. The traditional teaching courses and time schedule are uniform, which is not conducive to students to allocate learning time according to their own needs. Online teaching allows students to arrange their study time and space independently, just as some students said humorously: there is no delay in class when eating. At the same time, online teaching is actually one-toone teaching. Students can selectively arrange the learning content and learning methods according to their individual needs, personal characteristics, and learning styles. For example, during the epidemic prevention and control period, students have the teaching platform of the Ministry of Education, the classroom of famous teachers of the Provincial Department of Education, and the live broadcast classroom of teachers of various schools. Then students can use these resources comprehensively according to their needs and selectively broadcast them. Another example is that each student's superior subjects and disadvantaged subjects are different. Students can arrange more time in the disadvantaged subjects, while speed up the learning progress in the superior subjects. It is conducive to students' targeted learning. With the separation of teachers and students in online teaching, the students will gradually get rid of their dependence on teachers and gradually form a sense of independent development. Online teaching allows students to have a more relaxed learning atmosphere, autonomy and happiness, which is conducive to improving their internal motivation for learning and growth.

\subsection{It strengthens the ability of collaboration between teachers and students}

The interactivity and collaboration of online teaching enhance the communication and ability of cooperation btween teachers and students. In online teaching, students are not studying independently. They are in a real networked social interaction. They have study groups, class groups, friend groups, etc. They will comment on the same issue in the group. By proposing questions, brainstorming and soliciting answers in the groups, each problem solving will bring them great pleasure and further enhance the motivation for learning. Just as what a famous teacher excitedly talked about the experience of teacher-student interaction: when I answered questions online, I found that the 
microphone echo was particularly large when students asked questions, and it made the process of answering questions harder. So I called on students in the class groups to study and solve this problem. The next day, the teacher saw that some students in the group had already solved the problem. The method was simple: when the student asked a question, the teacher mutes the microphone. When the teacher answered, the students mute the microphone. The teacher praised the student's ability for problem solving with great excitement in the class. And I believe this student will also be very encouraged. The content of communication and collaboration between students is more abundant. Everyday, students will find problem-solving competitions in the class group. The person who makes the problem is excited and the person who solves the problem is proud. There are other students in the group who like it. The students feel the inspiration from the teacher or peers. The mutual help and collaboration between teachers and students can greatly broaden their horizons and broaden their knowledge structure, which is conducive to enhancing students' communication and team building skills.

\section{Insufficiency analysis of online courses during the epidemic}

\subsection{The lack of teacher guidance}

In the traditional classroom teaching practice, teachers can lead and adjust the teaching progress according to the teaching goals and academic conditions, and teachers and students can communicate face-to-face. The form of teaching based on the DingTalk software emphasizes the independent learning ability and learning methods of students. Students can learn and receive knowledge autonomously while watching online courses, but the mastery of knowledge only stays at a shallow level. Therefore, teachers need to explain and analyze the knowledge in depth. At the same time, the teaching by using DingTalk is more about the teaching content of PowerPoint. It is difficult to play the role of teacher's guide. For the detailed problems of some students, teachers cannot explain and tutor in time, which is prone to confusion of knowledge points and grammar. So the effect of online teaching is affected.

\subsection{Decline of active challenging}

In the classroom teaching practice, the interpretation of English language points and knowledge has a certain degree of abstraction. This way can just explore students' problem awareness, making them propose, think about and deal with problems. In the online classroom teaching, teachers are more likely to give knowledge by the three-dimensional pictures, it is easy for students to mistakenly believe that English knowledge is only in the form of visualization, which is not conducive to stimulating their temptation for challenge. It will not be easy for them to deep analyze And extend language and knowledge points. As a result, it makes the students' English learning worse and enables them to form bad learning habits.

\subsection{It has not paid attention to self-control}

In a real classroom teaching environment, teachers can monitor the overall student's learning status and acceptance, and can restrain some students' distracting behavior in time. However, the DingTalk network platform relies more on students' own learning ability to conduct inquiry, and has higher requirements on the ability of self-control and self-supervision of students in vocational school. It is good for the students with clear goals and clear plans, making them more quickly improve their language level and ability to promote their personalized development. However, for some students who lack ability of self-control, there is no teacher supervision and guidance in online teaching. Their understanding of knowledge is not deep enough, and the learning method lacks purpose and direction, resulting in a decline in academic performance.

\subsection{Distraction of attention in class}

Online teaching is extremely vivid, and students are in a state of gradual mental development. In this process, their attention is often attracted by the vivid display of multimedia, especially in the classroom of vocational school ${ }^{[1]}$. Students often only remember the pictures and animations displayed in multimedia after the class, and they are at a loss to know what the pictures and animations want to express. The rich online teaching resources will make students use their resources distractively and lead to inefficient learning.

\section{Analysis of the development prospects of the teaching of the online platform for English in vocational schools}

\subsection{Pay attention to learning feedback and control the teaching process}

In the practice of online teaching, a variety of complex factors can interfere with the teaching process. 
Therefore, teachers should comprehensively use a variety of teaching methods and forms to pay attention to the attraction of students' classroom attention, so that each student can submit online feedback in a timely manner. At this time, the teacher can improve aspects such as teaching speed and detailed explanation based on the feedback to better achieve the specified teaching goals. That said, the students' English quality and learning ability can be further developed and improved ${ }^{[2]}$. At the same time, it is necessary to integrate students' feedback information in various teaching sections, and select representative questions among them for centralized answering and explanation, help students better master and understand knowledge, and promote the development of English education informatization.

\subsection{Build interactive groups to improve student personality}

Restricted by the epidemic period, students can only obtain information and resources related to teachers and classmates through the Internet such as DingTalk. English education should not only focus on the scope of knowledge transfer, but also focus on the strengthening of language application and communication skills. When teachers use the platforms such as DingTalk, QQ and WeChat to form collaborative learning groups, they can bring students in a long distance together through the Internet. Students pay attention to and analyze knowledge maps, text and images in various online courses or information exchanges. And students can virtually talk about and exchange the English knowledge to establish a human-computer group for information interaction. At this time, teachers must overcome the limitation of the information platform and create an effective learning environment for group cooperation and coordination in order to allow students to collide and exchange views in interpersonal communication, deepen their ideas of knowledge, and improve their personality and cultivate their healthy psychology.

\subsection{Pay attention to emotions of spoken English and improve language level}

Due to the difference between Chinese and English expressions, students in secondary vocational school do not have a good grasp of the emotions expressed in English. Teachers are just able to use the online teaching practice to make students experience the tone and emotion of authentic spoken English, and make full use of Internet resource technology to edit and share classic movie clips. And they encourage students to talk to each other about the combination of images and expressions, and organize students to play roles in the movies so that they will have a happy learning attitude, and truly integrate into it. Secondly, emotion is an important factor for learners to control their own learning state and affect learning effect. Therefore, the selection of movie resources or other teaching PowerPoints should conform to the characteristics of professionalism, personalization, and school-based teaching of English in vocational school, so that students can freely choose learning content and arrange learning progress and better satisfy their desire and interest for knowledge. It can also mobilize the enthusiasm of learners through the roleplay of movie scenes, so that they have a pleasant emotional experience of spoken English, greatly improving learning efficiency.

\subsection{Multiple intelligent evaluation and integration into situational teaching}

The online assessment system based on DingTalk is also accurate, objective and procedural. Teachers should play a role in the teaching process, connecting vivid pictures and abstract knowledge to better guide students from experiential learning into understanding learning. Teachers should pay attention to the cultivation of students' ability to use English in the workplace, use multiple intelligences to evaluate students, and promote the development of students' intelligence in many aspects to better adapt to future work and study, such as, the assessment of students' skill level, professional qualities, and professional development ${ }^{[3]}$. They can make the new evaluation method conform to the growth rules of students, which is more conducive to the cultivation of technical skills in vocational education. At the same time, English online teaching can enhance the interest of the classroom and promote the mutual progress between teachers and students. Teachers should use modern educational technology to create a pure cultural situation, create a real life situation and a good dialogue situation. Teachers should also create a strong reading situation and predict a strong learning atmosphere to enhance students' interest in learning. It improves students' academic performance, and develops students' overall intelligence. On the other hand, the application of modern educational technology in situational teaching can promote the renewal of teachers' teaching ideas, the improvement of teaching methods and the transformation of evaluation methods, 
thereby improving their professional teaching ability and information teaching level.

\section{Conclusion}

Based on the above description, the DingTalk-based Internet platform has played a great role in supporting English teaching. It can only be used as a teaching aid and learning method. It cannot replace the traditional face-to-face teaching model, and the teacher's guiding role is reflected throughout the entire teaching process. Practice has proved that English teaching in the Internet environment is conducive to inspiring students' innovative ability. The prospect of Internet teaching is very broad. It requires that the English teachers should update their ideas, knowledge, methods, and life-long learning. The use of Internet resources can broaden the horizons of higher vocational students, expand students' thinking, and improve students' English ability and literacy.

\section{References}

[1] Wang X. On the auxiliary role of multimedia in English teaching in vocational schools[J]. Software (Education Modernization) (electronic version), 2019, 000(006): 126.

[2] Wang Q. Research on innovative teaching practice of vocational English in a smart campus environment[J]. Journal of Zhejiang Business Technology College, 2017, (1).

[3] Wu XY. Talking about the Reform of English Teaching in Secondary Vocational Schools under the Background of "Internet+"[J]. Chinese and Foreign Exchanges, 2017, 000(031): 110-111. 